\title{
Diálogos entre a fala e a escrita
}

Agnes Francine de Carvalho Mariano ${ }^{1}$ 


\section{Resumo}

O presente artigo retoma algumas teorias sobre mudanças na percepção, mentalidade e organização social decorrentes do modo de comunicação predominante: oral, manuscrito, tipográfico, eletrônico. Em seguida, busca localizar proximidades entre a fala e a escrita, especialmente após a "retribalização" propiciada pela comunicação eletrônica e digital. E também indica interseções que sempre existiram entre os gêneros orais e escritos.

\section{Palavras-chave}

Oralidade, escrita, gêneros.

\section{Abstract}

This article revisits some of the theories about changes in social perception, mentality and organization resulting from the predominant mode of communication: oral, handwritten, typographical, electronic. It then seeks to find similarities between speaking and writing, especially after the "retribalization" caused by electronic and digital communication. Moreover, it points out the intersections that have always existed between oral and written genres.

\section{Keywords}

Orality, writing, genres. 
Nas últimas décadas, a reabilitação da oralidade tem sido um movimento frequente. A acessibilidade dos aparelhos de gravação permitiu, por exemplo, que historiadores começassem a trabalhar com materiais orais: relatos, entrevistas, discursos, cantos, etc. Em uma área que sempre encarou como documento histórico apenas materiais escritos, foi um movimento e tanto. $\mathrm{Na}$ Comunicação, o interesse simultâneo pelo oral e o escrito é inevitável. Seja no rádio, TV ou internet, diversos gêneros orais estão presentes. E mesmo quando se trata de gêneros escritos, na maioria dos casos, gêneros orais (como a entrevista) participam da produção da escrita. Entre linguistas, as relações entre a fala e a escrita têm sido tema de muitas pesquisas. A busca é superar a visão dicotômica dessa relação. Ao invés de amplificar as diferenças, reconhecer e valorizar as interseções, levando em conta que tanto uma quanto outra podem ser influenciadas pelas regras da escrita ou recursos da fala. Que a relação não é de antagonismo, mas complementar, como modalidades que são de apropriação da língua.

Entretanto, o que justifica esse esforço de valorização da oralidade é que, a despeito da importância que ela nunca deixou de ter, essa perspectiva não é consensual. Na definição de Marcuschi (2007, p. 17), "sob o ponto de vista mais central da realidade humana, seria possível definir o homem como um ser que fala e não como um ser que escreve". Mesmo assim, seja entre leigos ou especialistas, ainda é muito presente uma excessiva valorização da escrita, associada a um desprestígio da oralidade. A escrita é avaliada como superior, mais correta e precisa que a oralidade. As consequências dessa concepção são profundas. Antonio Faundez (2008) chega a afirmar que a perspectiva antagônica da relação entre oralidade e escrita está entre os principais motivos do fracasso de programas de alfabetização na África e América Latina.

Para dessacralizar a escrita, sem mitificar a oralidade, a busca aqui será a de entender como elas se constituem, como nos afetam, como foi construída a valorização social da escrita, as mudanças trazidas pela comunicação de massa e onde fala e escrita se aproximam. Nas últimas décadas, alguns pesquisadores 
estudaram as semelhanças e diferenças entre culturas orais e povos que fazem uso da escrita. Investigaram mudanças na percepção, mentalidade e organização social decorrentes da popularização do alfabeto, da impressão tipográfica e, mais recentemente, da eletricidade e eletrônica aplicadas à comunicação. Walter Ong, Jack Goody e Marshall McLuhan estão entre os mais representativos. Por isso serão aqui recuperados alguns dos principais pontos da reflexão desses autores sobre o tema.

\section{Oralidade}

A linguagem oral é a base, o fundamento. Para alguns pesquisadores, a fala seria uma capacidade inata, como andar. Para outros, envolveria também um certo estímulo ambiental, o que a tornaria culturalmente adquirida. E há ainda outros, explica Mary Kato (1986), que acreditam numa evolução: teríamos um limite inferior de desenvolvimento linguístico bioprogramado e um limite superior, que seria atingido com o estímulo cultural. Como a antecede, é a oralidade que permite à escrita existir: "A expressão oral pode existir - e na maioria das vezes existiu - sem qualquer escrita; mas nunca a escrita sem a oralidade" (ONG, 1998, p. 16).

E como a imersão na oralidade afeta aqueles que participam integralmente desse mundo? Quando trata de culturas intocadas pela escrita, um dos primeiros aspectos que Walter Ong aborda é a necessidade de reter e transmitir o conhecimento por meio da memória. O que afetaria a forma como ele se apresenta: padrões rítmicos, repetições, antíteses, rimas, epítetos, expressões formulares, provérbios. Ou seja, em padrões que facilitam a memorização e repetição. Pelo mesmo motivo, pensamento e expressão tenderiam a ser mais aditivos que subordinativos nas culturas orais. As informações vão sendo conectadas por um somatório de "e". Outra característica é que as fórmulas prontas com valores agregados são muito usadas: "Não o soldado, mas o soldado valente; não a princesa, mas a bela princesa" (ONG, 1998, p. 49). 
E a lista de características resultantes da predominância da oralidade prossegue. A redundância seria outro recurso necessário. O acréscimo de informações deve ser lento e repetitivo, para que seja compreendido e fixado. Com a redundância, vem o excesso, pois a hesitação é prejudicial. Para Ong (1998), a dependência da memória e a necessidade da repetição estimularia uma "conformação mental altamente tradicionalista e conservadora". Valorizase mais então o que já se sabe, o ancião, que o jovem inovador. Uma ideia importante para Ong (1998) é a de que, entre povos orais ou que ainda preservam muito da "estrutura mental da oralidade", não há o pensamento analítico, o recurso a categorias abstratas. Daí, o processo de reter e compartilhar o conhecimento se ampararia no que está próximo: as ações humanas. Entre essas ações, procura-se as que tocam mais intensamente a memória: com tom agonístico, de luta; uma expressão exagerada de louvor; valorização dos triunfos, de personagens fortes, com façanhas impressionantes, e do bizarro. Como são contadas em público, as narrativas orais tendem a privilegiar as vitórias e deixam cair no esquecimento os vencidos, por isso os personagens heroicos são os mais lembrados.

Entre as dezenas de milhares de línguas que já foram faladas no mundo, a imensa maioria não teve escrita, além do quê, a invenção da escrita ocorreu em período bastante tardio em relação à presença do homem no planeta, estimada em 200 mil anos. A invenção da escrita cuneiforme pelos sumérios data de 3.500 a.C. e marca o fim da pré-história. Já o primeiro alfabeto, criado pelos semíticos, é de 1.500 a.C. Dele derivam os outros alfabetos criados no mundo, diz Ong (1998), acrescentando que os gregos deram contribuição fundamental ao criarem o primeiro alfabeto com vogais.

Foi o silabário fenício que os gregos tomaram emprestado para a base de sua escrita. Mas o que era feito apenas esporadicamente pelos fenícios, isto é, a colocação da vogal depois da consoante, firmou-se entre os gregos como norma. Passou-se assim da escrita silábica para a escrita alfabética (KATO, 1986, p. 16). 
A maioria dos autores concorda que a motivação central para a criação e uso da escrita pelos sumérios da Mesopotâmia foi econômica, ainda que tenha se iniciado nos templos.

Levando-se em conta o predomínio da palavra falada no mundo antigo e medieval, parece compreensível que a ela fossem associadas ideias como verdade, força e poder mágico. Mesmo após a invenção da escrita. A emissão de um som era entendida como ação, evento. Daí, "o fato de os povos orais comumente - e muito provavelmente em todo o mundo - julgarem as palavras dotadas de uma potencialidade mágica" (ONG, 1998, p. 43). Desenvolveramse então ritos para o ato de proferir as palavras e, assim, alcançar os efeitos pretendidos. Força e poder que geraram também confusões entre povos com e sem escrita. Pois estes últimos, em alguns casos, operando com uma lógica da oralidade, acreditavam que, apoderando-se de textos escritos, poderiam se beneficiar do poder dessas palavras.

Hoje nos parece tão natural que o documento escrito seja mais "confiável", que pode ser difícil crer que, durante muito tempo, o pensamento comum fosse justamente o contrário. São numerosos os exemplos da valorização do oral, especialmente na fase da escrita manuscrita. Como afirma Kato (1986, p. 34), a escrita era considerada vulnerável "a todo tipo de falsificação de informação, não sendo uma fonte fidedigna como a autoridade oral". Ong (1998) cita os estudos de Clanchy sobre uso da escrita na Inglaterra dos séculos XI e XII, para mostrar como as pessoas duvidavam da veracidade dos documentos e preferiam continuar confiando nos testemunhos orais. Vem da Idade Média o hábito de testar a perícia intelectual dos estudantes pelo debate oral e nunca pela escrita, um costume que sobrevive hoje na defesa oral das pesquisas de pós-graduação.

Pelo menos até o século XII na Inglaterra, a verificação de cálculos financeiros escritos ainda era feita auricularmente [...] ela ainda está inscrita em nosso vocabulário: ainda hoje falamos de 'auditoria', isto é, de 'ouvir' livros de contabilidade (ONG, 1998, p. 137). 
Esses e outros exemplos demonstram que o aprendizado da escrita não afetou imediatamente a influência da oralidade. Há um longo processo de interiorização da tecnologia para que aconteçam mudanças mais profundas. $\mathrm{Na}$ cultura manuscrita da Idade Média, por exemplo, a oralidade estava presente na escrita, na leitura, na assumida intertextualidade e de muitas outras formas: "[...] não faltam indicações de que 'ler', ao longo dos tempos antigos e medievais, significava leitura em voz alta" (MCLUHAN, 1972, p. 126). Publicar equivalia a recitar publicamente, entre gregos, romanos e mesmo após o livro e a leitura terem se popularizado. Tal vinculação à palavra falada, é claro, fazia do texto antigo um texto para ser lido, portanto, afinado com outros princípios, como os da retórica. Usava-se com frequência o trabalho de escribas, para quem os livros eram ditados. E mesmo quando escritos do próprio punho, frequentemente o autor o ditava em voz alta para si mesmo. O tom de conversa também era presente, por isso muitos livros começavam com: "'Hic habes, carissime lector, librum quem scripset quidam de...' (Aqui está, caríssimo leitor, um livro que fulano escreveu sobre...)" (ONG, 1998, p. 144).

Na verdade, a noção de autoria era bastante distinta da atual. Copiar textos alheios, muitas vezes sem citar autoria e sem atribuir a si mesmo a autoria do livro eram práticas comuns. Goldschmidt (apud MCLUHAN, 1972, p. 184) afirma:

\footnotetext{
A indiferença dos eruditos medievais pela exata identidade dos autores, em cujos livros estudavam, é incontestável. Os próprios escritores, por outro lado, nem sempre se davam ao trabalho de 'pôr entre aspas' o que extraíam de outros livros [...] hesitavam em assinar de maneira clara e inconfundível até mesmo o que evidentemente era trabalho dêles próprios.
}

Segundo Chaytor (apud McLuhan, 1972), copiar um livro e fazê-lo circular seria considerada uma "ação meritória".

Impedimentos técnicos contribuíram para limitar a influência da escrita nos primeiros tempos. A produção de um livro manuscrito era algo trabalhoso e sujeito a erros. A dificuldade se estendia à leitura, pois a escrita manual 
compromete a legibilidade e eram usadas muitas abreviações, para facilitar o trabalho. Por isso, eles eram escassos e valiosos. Os estudantes precisavam produzir os seus próprios livros, copiando à mão o que Ihes era ditado em sala. Alguns desses foram parar em bibliotecas de mosteiros, eram muito consultados e estão entre os primeiros a serem publicados.

\section{Cultura escrita}

Se até aqui destacamos a importância da cultura oral, mesmo após a escrita, não se pode negar, entretanto, que os distanciamentos também existiram. E que, ao longo dos anos, foram assumindo novos contornos. Entre os motivos para a progressiva valorização "do que está escrito", um dos principais é a capacidade de fixar dados. Goody (1987) enumera exemplos que demonstram as consequências disso nas relações econômicas. Sem a escrita, dependia-se inteiramente do que a memória conseguia reter:

\footnotetext{
Devido aos limites da memória humana, as senhoras ganaenses observadas por Hart, que forneciam comida a crédito a empregados de um recinto de transportes, e cobravam pagamento aos portões no fim do mês, só podiam tratar de um número restrito de clientes e de um número restrito de diferentes tipos de transacção (GOODY, 1987, p. 103).
}

Com a escrita, os dados podem ser retidos num volume muito acima da capacidade humana de memorização e, sendo autênticos, diminuem os riscos para ambas as partes. A escrita permite também a comunicação de um indivíduo consigo mesmo e, assim, a possibilidade de reelaborar o próprio trabalho.

Desde o começo, a escrita vem proporcionando privilégios aos que a dominam. Goody (1987) lembra que, nas religiões em sociedades letradas, o conhecimento sempre estava sob o controle de eruditos, guardiões e intérpretes primordiais dos textos sagrados. Tal situação se converte em poder religioso, político e econômico. 
Os letrados religiosos pensam muitas vezes que, idealmente, o reino de Deus deveria vir a ter lugar na terra e a classe sacerdotal deveria administrar os seus bens, uma ideia incorporada no papado medieval, no califado do Islão e na ideologia xiíta do Irão contemporâneo (GOODY, 1987, p. 36).

O domínio da escrita significava o acesso a bens. Para Goody (1987, p. 34), em nenhuma outra área ele teve papel tão importante quanto no registro de propriedades:

De especial importância eram as doações de terra, grandes quantidades da qual caíram sob a alçada de igrejas letradas - na Europa ocidental, um terço da terra cultivável, aproximadamente o mesmo no Ceilão medieval e em partes da Índia meridional, quantidades consideráveis no Nepal e no Tibete e quantidades substanciais sob o Islão, atingindo de novo um terço no Antigo Egipto. Com efeito, a instrução é não só um dos fins como é também o meio, encontrando-se criticamente envolvida no processo de aquisição em si, dado que a redacção de testamentos e documentos escritos muitas vezes efectua, legitima mesmo, a alienação da propriedade da família ou linhagem a favor da igreja.

Para os não-letrados, as consequências da progressiva valorização da escrita foram graves. Eles podem facilmente ser espoliados, inclusive porque os "dados" fixados pela escrita podem ser falsos. Goody (1987) cita o caso da propriedade comunal de terras, presente entre alguns povos tradicionais, como os LoDagaa, do Gana. Isto é, quando não existe um único proprietário, porque "grande número de pessoas têm direitos diferentes sobre a mesma parcela de terreno" (p. 176). Quando a lógica da propriedade exclusiva, predominante no mundo letrado, é imposta pelos novos dirigentes, os não letrados são sempre prejudicados. A posse deve ser atribuída a apenas um indivíduo, excluindo todos os direitos de amigos e parentes. Ocorre também que, para conseguir financiamentos e realizar benfeitorias, exige-se a comprovação de posse de áreas maiores que as usuais entre esses povos, o que acentua a concentração nas mãos dos que conseguem mais rapidamente dialogar com as exigências da cultura escrita. Assim como acontecia no contexto religioso, cada vez mais o fato de ser letrado vai se tornando condição necessária para se ter acesso a 
certos postos. Levando-se em conta tantos privilégios envolvidos no domínio da escrita, fica mais fácil entender a restrição que sempre houve sobre o acesso à instrução e à produção de livros.

\section{No mundo tipográfico}

Para alguns autores, entretanto, ainda que a escrita tenho trazido mudanças sociais, as transformações mais significativas só vão ocorrer a partir do século XV. Em seu livro A galáxia de Gutenberg (1972), como anuncia desde o título, McLuhan credita essas transformações à impressão por tipos móveis, que tornou possível a reprodução em série de textos impressos. Estabelecese uma cadeia produtiva mais complexa, reelaborações do produto livro e a possibilidade de criação de inúmeros outros produtos. Como os textos se tornam mais acessíveis e legíveis, a leitura passa a ser mais rápida, silenciosa, solitária. E, pelas caraterísticas do texto impresso, uma leitura linear, uniforme. É nesse momento que a ênfase no sonoro perde espaço para o visual. Para McLuhan (1972, p. 133), o que ocorre em função desse deslocamento é bastante transformador: "A diferença entre o homem da palavra impressa e o da palavra manuscrita é quase tão grande quanto a que existe entre o nãoalfabetizado e o alfabetizado".

McLuhan (1972, p. 52) fala em culturas auditivas e culturas visuais, nas quais "os valores visuais têm prioridade na organização do pensamento e da ação". E prioridade é entendida como uma forma de anestesiar os outros sentidos, que, no mundo sonoro, operam em conjunto, fazendo do "povo do ouvido" um homem mais integrado ao mundo. A ideia é que a ênfase na visão fragmenta, separa, individualiza. A tese defendida por alguns é a de que a cultura sonora alimenta o pertencimento grupal enquanto a cultura visual dá ênfase ao indivíduo. Um pertencimento grupal que tolheria ambições e iniciativas pessoais, o mundo interior, ao mesmo tempo em que estimularia demonstrações exteriores de emoções, inclusive agressivas. Já o individualismo da cultura visual daria ênfase 
ao mundo interior, às decisões pessoais, tendo como preço a destribalização, a criação de um "homem dividido, partido, esquizofrênico, como todo letrado ou alfabetizado tem sido desde a invenção do alfabeto fonético" (MCLUHAN, 1972, p. 45). Nas culturas letradas, desde jovem se adquire "objetivos internalizados". Para McLuhan (1972, p. 53), uma consequência do ponto de vista fixo inerente à leitura pós tipografia: "Um caráter estável e firme é um caráter dotado de perspectiva inflexível, de uma postura visual quase hipnotizada, por assim dizer". No mundo auditivo, a perspectiva é multidirecional, como o som.

A tipografia acentuaria também a tendência ao isolamento nos processos de leitura e escrita. Ao escrever, aquele que escreve agora está só.

O escritor precisa construir um papel ao qual leitores ausentes e muitas vezes desconhecidos possam se moldar. Até mesmo ao escrever a um amigo íntimo preciso construir uma ficção de estado de espírito para ele (ONG, 1998, p. 118).

Isolamento similar é solicitado pela leitura, que, até então, tinha sido frequentemente uma atividade social. Ao ponto de, não havendo a condição de isolar-se, a leitura ser severamente afetada, afirmam alguns:

Os professores de crianças de áreas pobres, hoje, possuem uma consciência aguda de que, muitas vezes, o maior motivo para um desempenho medíocre é que não há nenhum lugar em uma casa cheia de gente onde um menino ou uma menina possam estudar com proveito." (ONG, 1998, p. 149).

Mesmo que a tendência à rigidez tenha sido amplificada na cultura tipográfica, muitos já a identificam na cultura escrita em geral. Goody (1987) dá como exemplos o contexto jurídico e o religioso. No jurídico, em sociedades sem escrita, "as normas só têm uma existência verbal, oral, de modo que as regras que já não são aplicáveis tendem a escapar-se do reservatório de memória" (p. 161). Situação mais complexa é lidar com as mudanças num ambiente com escrita, por isso tantos anacronismos são mantidos por décadas nas legislações. No campo religioso, Goody (1987, p. 25-26) identifica o mesmo princípio: 
Nas igrejas letradas, o dogma e os serviços são rígidos [...] o credo é recitado palavra por palavra, as Tábuas do Senhor aprendidas de cor, o ritual repetido textualmente. Se tem lugar uma mudança, ela toma com frequência a forma de um movimento de cisão.

Uma outra consequência de todas essas mudanças trazidas pela difusão da escrita impressa foi o desenvolvimento da noção de autoria. Se antes, como vimos, a ideia corrente era a de compartilhar um conhecimento que vinha da tradição ou dos sábios do passado, na era tipográfica, a perspectiva muda. Nasce a propriedade privada das palavras, surgem leis para proteger os direitos de quem edita e escreve.

A cultura impressa deu origem às noções românticas de "originalidade" e "criatividade", que separam mais ainda uma obra individual das outras obras, vendo suas origens e seus significados como independentes da influência exterior, ao menos de um ponto de vista ideal" (ONG, 1998, p. 152).

A "ideia" de autoria se relaciona com a sensação produzida pela escrita de que o pensamento foi isolado, é independente. Essa sensação de "completude" foi ainda mais acentuada com o livro impresso, o que colaborou na modificação do estatuto de verdade, que antes era atribuído à fala, e vai migrando para "aquilo que foi escrito e impresso". Até porque, o que foi escrito e publicado nunca será efetivamente refutado. A não ser que seja destruído, um livro continuará sempre a afirmar o mesmo.

\section{Continuidades}

E para onde caminhamos agora? Primeiro é preciso lembrar que, da popularização da escrita impressa para cá, muitas coisas relevantes aconteceram em relação aos meios pelos quais nos comunicamos: telefone, cinema, rádio, televisão, computadores, internet. E, ao que tudo indica, modificando novamente o equilíbrio de forças. Para falar em termos mcluhanianos, o predomínio inconteste do visual sobre o sonoro foi relativizado. Com essas novas formas de comunicar, outros sentidos foram reconvocados a participar. Um tempo em que "a visão, o som, e o movimento são em toda extensão simultâneos e globais" (MCLUHAN, 1972, p. 22). O que, novamente, teria modificado a nossa forma de perceber, pensar e agir. 
A televisão completa o ciclo do sensorium humano. Com o ouvido onipresente e o olho em movimento, abolimos a escrita, a metáfora acústica-visual especializada que determinou a dinâmica da civilização ocidental.

Na televisão ocorre uma extensão do sentido ativo do tato, exploratório, que envolve todos os sentidos simultaneamente, e não só a visão. Você tem que estar com a TV. Porém, em todos os fenômenos eletrônicos, o visual é apenas um dos componentes de uma interação complexa (MCLUHAN, 2011, p. 124).

Quando diz que "abolimos a escrita", McLuhan (2011, p. 45) certamente está falando sobre o fim do predomínio da experiência linear e uniforme proporcionada pela escrita.

O alfabeto é um construto de pedacinhos que não possuem significado semântico em si mesmos, e que têm que ser costurados em uma linha $[\ldots]$. Seu uso fomentou e encorajou o hábito de perceber todo o ambiente em termos visuais e espaciais - especialmente em termos de um espaço e de um tempo que sejam uniformes.

$\mathrm{E}$, possivelmente, ele estava também projetando um futuro no qual a escrita/visão e seus valores deixam de ser predominantes. Em outro momento, ele próprio havia afirmado: "Depois de um século de eletricidade, ainda se sente a presença dos antigos valôres da alfabetização, do individualismo, do privado da separação" (MCLUHAN, 1972, p. 35).

A metáfora usada para definir o que ocorre a partir do século $X X$ é a da retribalização, indicando semelhanças entre o que vivemos hoje e o antigo mundo, das tribos, em que a oralidade predominava. A ideia é a de que estaríamos vivendo um tempo novo, mas que, em vários sentidos, evoca o antigo. "Retornamos ao espaço acústico. Recomeçamos a estruturar o sentimento primordial, as emoções tribais das quais alguns poucos séculos de alfabetização nos divorciaram" (MCLUHAN, 2011, p. 64). Ou seja, um modo de perceber e viver mais integrado, pois a "tecnologia eletrônica fomenta e encoraja a unificação e o envolvimento" (p. 9), recriando, em outros termos, a experiência tribal. A sua frase síntese é: "A nova interdependência eletrônica recria o mundo à imagem de uma aldeia global" (MCLUHAN, 1972, p. 58). 
Esse novo tempo - cheio de estímulos simultâneos (sons, imagens, movimento) e que convoca a participação - se pareceria com o antigo também por sua dimensão mágica e mítica: "Qualquer criança ocidental cresce nessa espécie de mundo mágico da repetição, ressuscitado pela publicidade do rádio e da televisão" (MCLUHAN, 1972). Para McLuhan (2011, p. 113), mito é "o modo de consciência simultânea de um complexo grupo de causas e efeitos". Assim, o modo mítico de perceber o mundo é um modo que, ao invés de categorizar, separar, busca semelhanças, padrões e se move por eles.

O ponto delicado é que, como sempre, vivemos muitos tempos e paradigmas simultaneamente. As nossas experiências nos empurram em uma direção e as nossas crenças em outra: "Nossa tecnologia nos força a viver miticamente, mas continuamos a pensar fragmentariamente e em planos únicos e separados entre si" (MCLUHAN, 2011, p. 113). Para os mais novos, que já nascem e crescem imersos num contexto dominado pela eletricidade e eletrônica, é ainda mais conflitante:

O estudante não encontra meios de se envolver e não pode descobrir como o esquema educacional se relaciona com seu mundo mítico de dados eletronicamente processados e nem pode experimentar o que suas respostas claras e diretas Ihe trazem" (MCLUHAN, 2011, p. 101).

E conflitante também porque, muitas vezes, anseios desses jovens e demandas sociais não se equilibram: "O jovem de hoje rejeita as metas. Eles querem papéis a desempenhar. [...] Eles já não querem metas ou tarefas fragmentadas, especializadas" (MCLUHAN, 2011, p. 101).

Não foi apenas McLuhan quem viu a relação entre o novo contexto que vivemos, após os meios de massa, e a oralidade. Walter Ong (1998) acreditava que a tecnologia eletrônica nos levou à "era da oralidade secundária". Entre as semelhanças, ele enumera a "mística participatória", o estímulo ao comunal, o foco no presente e até o uso de fórmulas (padrões, clichês). Também cita diferenças entre a oralidade "primária" e a "secundária", como a presença da escrita e impressão, na segunda, inclusive porque "são essenciais para a 
manufatura e a operação do equipamento, assim como para seu uso" (ONG, 1998 , p. 155). Além disso, lembra que "a oralidade secundária dá sentido a grupos incomensuravelmente mais amplos do que os da cultura oral primária" (ONG, 1998, p. 155).

Em países como Brasil, que mescla ambientes letrados, não letrados e residualmente orais, as coisas podem ser ainda mais complexas. Seja na fala, seja no canto, as práticas orais gozam de um prestígio e têm um impacto muito expressivo, chegando a influenciar a escrita dos mais letrados:

O impacto da linguagem literária sobre uma sociedade como a brasileira, por exemplo, é ínfimo. Tradicionalmente somos um povo que lê pouco: nossas práticas sociais, mesmo entre as classes abastadas, sempre foram muito mais guiadas pela oralidade do que pela cultura livresca (BAGNO, 2003, p. 48).

Em seus estudos sobre a apropriação da escrita, Luria observou que, em etapas inicias de aquisição da escrita, predomina a influência da fala. "Na linguagem escrita desta pessoa, em parte se transferem os procedimentos da linguagem oral" (LURIA, 1986, p. 171-172). Enquanto que em momentos posteriores é a fala que será influenciada pela escrita: "Frequentemente, as regras desta linguagem começam a se transferir para a oral e o sujeito fala como escreve" (LURIA, 1986, p. 172). A isomorfia entre fala e escrita, ao que tudo indica, tem profunda relação com o gênero utilizado. Ou seja, existem gêneros (falados e escritos) que se aproximam mais da fala e existem gêneros (falados e escritos) que se aproximam mais da escrita.

\section{Gêneros}

Para analisar gêneros orais e escritos, Luiz Marcuschi (2007) utiliza as categorias "meio de produção" (sonoro ou gráfico) e "concepção discursiva" (oral ou escrita). Dessa forma, ele mostra que, longe de serem estáveis, fala e escrita variam. Como exemplo, analisa quatro gêneros textuais, mostrando 
como meio e concepção podem se inverter. Assim, uma "conversação espontânea" e uma "notícia de TV" têm em comum o meio de produção: sonoro. Entretanto, a concepção discursiva da primeira é oral e, da segunda, escrita. Já o "artigo científico" e a "entrevista publicada na Veja" (ping-pong) têm em comum o meio de produção gráfico, mas divergem na concepção discursiva: escrita, para o artigo, e oral, para a entrevista. Na sua formulação, fala e escrita apresentam um continuum de variações. Isto porque, ainda que se mantenha o meio de produção, quando se modificam as "práticas sociais de produção textual", os gêneros também se modificam e suas características. "Comunicações pessoais", "Comunicações públicas", "Textos instrucionais" e "Textos acadêmicos" são exemplos de campos nos quais operam gêneros escritos diversos como bilhetes, notícias de jornal, bulas e relatórios técnicos. Tão diversos que gêneros orais ligados aos mesmos tipos de práticas sociais ("Conversações", "Constelação de entrevistas", "Apresentações e reportagens" e "Exposições acadêmicas") serão mais parecidos com os similares escritos, ainda que utilizem meio de produção sonoro.

\footnotetext{
Com isto, descobrimos que, comparando uma carta pessoal em estilo descontraído com uma narrativa oral espontânea, haverá menos diferenças do que entre a narrativa oral e um texto acadêmico escrito. Por outro lado, uma conferência universitária preparada com cuidado terá maior semelhança com textos escritos do que com uma conversação espontânea (MARCUSCHI, 2007, p. 42).
}

Outras semelhanças foram identificadas em nossa relação com as palavras faladas e as palavras escritas. É sabido que, ao mesmo tempo em que falamos, vamos dando vida ao conteúdo e forma desse discurso. E na escrita? Há um planejamento prévio ao qual obedecemos fielmente durante o ato de produzir o discurso? Mary Kato (1986, p. 89) cita uma pesquisa de Bruce e outros autores que "nos abre os olhos para algo que acontece no ato da escrita: o processo da descoberta". Segundo uma concepção da época, as ideias nasceriam primeiro e depois seriam traduzidas em forma (escrita). Para Bruce e seus colegas pesquisadores, as coisas não ocorrem assim: "As ideias 
expressas podem ser geradoras de ideias antes não cogitadas. Nossos pontos de vista e nossas metas podem se modificar na evolução do ato de escrever" (KATO, 1986, p. 90). Portanto, exatamente como ocorre na fala, que mais facilmente transparece o ato de "criar ao ser dito" e a mudança de rumos e opiniões durante o ato de dizer.

\section{Considerações finais}

Reabilitar a oralidade, reconhecer a sua importância central em nossas vidas, a sua capacidade expressiva, o prazer que gera, os encontros que promove, pensam alguns, pode ser também um caminho para facilitar a aquisição da escrita. Isto porque "uma função nova se adquire através de uma forma velha e uma forma nova se adquire através de uma função conhecida" (KATO, 1986, p. 105). Portanto, o "já conhecido" auxilia a aquisição do conhecimento novo. É de Vygotsky o conceito de "zona de desenvolvimento proximal", que propõe a "assistência", a "cooperação", a facilitação da "imitação", para que a criança tome contato com aquilo que ainda não sabe e, assim, passe a dominar esse conhecimento. Partir dessas premissas significa aceitar que os estudantes inicialmente partem das suas "habilidades e conhecimentos da língua oral" (KATO, 1986, p. 135) e significa, no processo pedagógico, "fazer uso da experiência prévia do aluno com a linguagem" (KATO, 1986, p. 135), que é a linguagem oral. Por isso, respeitar a transição entre os gêneros - partindo daqueles já experimentados oralmente para outros que, aos poucos, vão se distanciando da fala - seria um cuidado necessário.

As interseções entre fala e escrita tornam-se ainda mais complexas quando observamos o ambiente digital. A escrita é essencial nesse contexto e, muito provavelmente, escrevemos mais hoje do que antes. A popularização da internet - com seus blogs, redes sociais, chats, sites com espaço para comentários, sistemas de comunicação em tempo real, de trocas de mensagens, etc. - tem ampliado as situações motivadoras da escrita. Mas de uma nova escrita, por 
meio de novos gêneros escritos que se modificam rapidamente. A proximidade com a "concepção discursiva" da fala é evidente, como afirma Marcuschi (2005, p. 29): "Esta escrita tende a uma certa informalidade, menor monitoração e cobrança pela fluidez do meio e pela rapidez do tempo". Essa "informalidade" certamente é um grande agente motivador. Ao mesmo tempo, afirma ele, "a ideia que hoje prolifera quanto a haver uma 'fala por escrito' deve ser vista com cautela, pois o que se nota é um hibridismo mais acentuado, algo nunca visto antes, inclusive com o acúmulo de representações semióticas" (MARCUSCHI, 2005, p. 19). Para citar apenas o exemplo do e-mail:

as mensagens eletrônicas podem partilhar as propriedades da carta tradicional, mas podem partilhar as propriedades do telefonema ou a comunicação face a face. Consequentemente, os e-mails transgridem os limites entre as noções tradicionais de comunicação oral e escrita (MARCUSCHI, 2005, p. 41).

Pontuação mínima, ortografias recriadas, siglas, abreviaturas, uso de imagens, criação de imagens com sinais de pontuação, fusão de números, letras e sinais, uso abundante de interjeições, maiúsculas e a simulação de segregadores vocais são alguns dos recursos explorados nessa nova escrita. E talvez venha desse hibridismo a milagrosa fluência de escreventes de todas idades na internet. 


\section{Referências}

BAGNO, M. A norma oculta: língua \& poder na sociedade brasileira. São Paulo: Parábola Editorial, 2003.

FAUNDEZ, A. "Alfabetização, pós-alfabetização e cultura oral na educação africana". In: GADOTTI, M. História das idéias pedagógicas. São Paulo: Ática, 2008.

GOODY, J. A lógica da escrita e a organização da sociedade. Lisboa: Edições 70, 1987.

KATO, M. No mundo da escrita: uma perspectiva psicolinguística. São Paulo: Ática, 1986.

LURIA, A. R. "Principais formas de alocução verbal. Linguagem oral (colóquio e monólogo) e linguagem escrita". In: LURIA, A. R. Pensamento e linguagem: as últimas conferências de Luria. Porto Alegre: Artes Médicas, 1986.

MARCUSCHI, L. A. Da fala para a escrita: atividades de retextualização. São Paulo: Cortez, 2007.

Gêneros textuais emergentes no contexto da tecnologia digital. In: MARCUSCHI, L.A.; XAVIER, A.C. (orgs.) Hipertexto e gêneros digitais: novas formas de construção do sentido. Rio de Janeiro, Lucerna, 2005.

MCLUHAN, M. A galáxia de Gutenberg: a formação do homem tipográfico. São Paulo: Editora Nacional, Editora da USP, 1972.

; FIORE, Q. O meio é a massagem: um inventário de efeitos. Rio de Janeiro: Ímã Editorial, 2011.

ONG, W. Oralidade e escrita: tecnologização da palavra. Campinas: Papirus, 1998. 